\title{
ILAORMACION de una conciencia jurídica en la prédica de Manuel González Prada
}

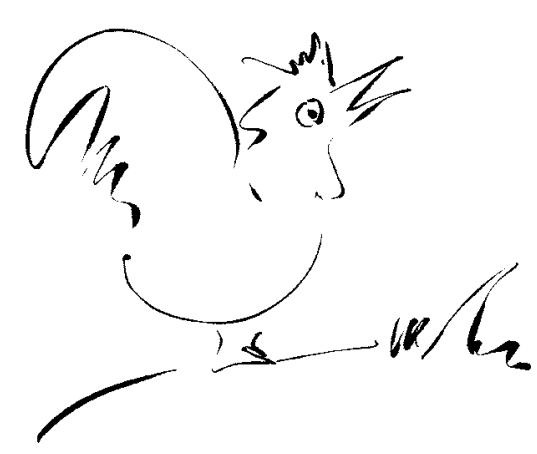

El presente ensayo repasa la trayectoria de Manuel González Prada y el contexto político y sociocultural del Perú de su época, alrededor del célebre Discurso en el Politeama, para repasar las ideas de este intelectual alrededor de lo que debería ser la nación peruana, y como ayudó a construir un marco legal para generarla.

Palabras clave: nación, ciudadanía, Constitución.

\section{Resumen}

La ensayística de González Prada no solo es de naturaleza política al señalar los vicios del poder y diseñar el diagnóstico de los males sociales que afectan al Perú, sino que, sin basarse en normas constitucionales y legales ni en la teoría del Derecho, con expresiones incuestionablemente estéticas, busca que los peruanos afectados por la derrota en la guerra, la desigualdad, la injusticia, la discriminación y la explotación se sacudan del desconcierto conformista y adquieran una conciencia jurídica que los haga pensar en que la justicia, la libertad, la igualdad, la dignidad, el desarrollo, el trabajo y la educación es un derecho y no una dádiva del gobernante y del poderoso.

Por eso la insistencia en los mismos temas, su verbo acusador, su prosa acerada, sus metáforas antitéticas para a través del contraste impactar en el ánimo de la persona movilizándola hacia el cambio. Un buen ejemplo es el Discurso en el Politeama.

\section{Objeto}

Desde las nuevas lecturas a la prosa de González Prada, es factible advertir perspectivas de identificación y explicación no percibidas anteriormente. Las investigaciones de la obra integral de Prada se han incrementado con una variedad de ópticas, siendo materia de mayor interés desde el punto de vista de las ciencias sociales.

Este estudio tiene como propósito esbozar y proponer una vinculación del ensayo gonzalezpradiano entre la literatura y el derecho, lograda a través de una estrategia de composición del texto que no la presenta de modo objetivo con referencias a normas legales, sino que se hace tangible en el resultado intelectual de la interpretación como argumento tácito que le da consistencia y contundencia a su mensaje.

Con esta intención, se ha escogido un ensayo: el Discurso en el Politeama, pronunciado el 29 de julio de 1888 para llevar a cabo el proceso de análisis, interpretación y comentario del texto.

La propuesta es pedagógica y está dirigida a estudiantes de Derecho como un ejercicio de hermenéutica literario-jurídica.

\section{Líneas de vida}

En función al objetivo trazado y en tanto factores coadyuvantes para una coherente interpretación, se 
hace aconsejable escoger algunas líneas de vida como la educación, el ambiente familiar, el contexto social y gubernamental; el panorama cultural e ideológico que dejan el rastro de una influencia en la composición del texto.

\subsection{Su educación}

Ateniéndonos a la cronología hecha por Marlene Polo, avalada por Luis Alberto Sánchez (1976), Manuel González Prada nació el 5 de enero de 1844, en Lima, como el tercer hijo de don Francisco González de Prada y Marrón de Lombera y de dońa Josefa Álvarez de Ulloa, casados en 1838 .

A los siete años de edad inicia su educación escolar en Lima, que se ve interrumpida por el traslado de la familia a Chile por un corto lapso de dos años. Allá, "es matriculado en el Colegio Inglés de Valparaiso, dirigido por un inglés y un alemán” (1976: 74).

De vuelta en Lima, reanuda su escolaridad en el Seminario de Santo Toribio, que abandona a corto plazo.

Entre 1860 y 1864 cursa estudios en el Convictorio de San Carlos, truncando su formación profesional de abogado por razones de su temperamento personal e incompatibilidad con sus expectativas de vida.

Complementa y amplía su bagaje cultural el autoaprendizaje proveniente de sus lecturas intensas y permanentes.

\subsection{Su familia}

Se trata de un hogar de ambiente conservador, católico y de linaje palaciego. Su más remoto antecedente genealógico se ubica en el siglo $\mathrm{XV}$, en la persona de Andrés de Prada, "paje del emperador Carls V... y también... Secretario de Estado de los Reyes Felipe II y Felipe III" (1976:69). Su pariente más cercano es don "Joseph González de Prada, Contador Oficial de las Caxas de Salta de Tucumán, por lo cual viaja a Buenos Aires" (1976: 70).

Joseph González de Prada viene a ser el abuelo paterno de don Manuel. Se casa en Cochabamba con doña Nicolasa Marrón y Lombera, quien será la abuela paterna del autor del Discurso.

La familia González de Prada y Marrón de Lombera aparece en Arequipa, ciudad en la que nace Francisco, su padre.
A Manuel González Prada le toca una época de literatura romántica con estilos personales, que no va con su pensamiento, su actitud frente a la vida, ni su gusto estético. Dentro de su línea, de búsqueda de formas nuevas y temas ligados con la noción de Perú, en la poesía escribirá las denominadas Baladas peruanas, dentro del género lírico, consecuentemente, solo sentimental.

\subsection{El contexto social y gubernamental}

La vida de Manuel sintetiza un discurrir entre el Combate del 2 de mayo de 1866 y la guerra de 1879 contra Chile. Dentro de tales acontecimientos ocurren los enfrentamientos caudillistas que tienen como personajes a Castilla, Vivanco; Echenique; Mariano Ignacio Prado; Cáceres, Piérola, Iglesias; Morales Bermúdez, Balta, entre otros.

En su temprana infancia don Manuel percibirá los vaivenes políticos al ser su padre vicepresidente y ministro del general Echenique. Al retorno de la familia, su padre será designado alcalde de Lima. Antes, se desempeñó como juez de primera instancia y vocal superior, tal como ha rastreado Manuel Zanutelli Rosas (2003).

La familia perteneció al sector social pudiente con posición política expectante. Conformará el sector minoritario poseedor del poder político que domina a la mayoría campesina sumida en la explotación, la ignorancia y la desigualdad ante la ley y sin oportunidades ni posibilidades de ascenso social individual o colectivo.

\subsection{El ambiente cultural e ideológico}

A Manuel González Prada le toca una época de literatura romántica con estilos personales, que no va con su pensamiento, su actitud frente a la vida, ni su gusto estético. Dentro de su línea, de búsqueda de 
formas nuevas y temas ligados con la noción de Perú, en la poesía escribirá las denominadas Baladas peruanas, dentro del género lírico, consecuentemente, solo sentimental que, a través de la vía poética, lo aproxima a un sentimiento de país que solo logra la compasión, pero no servirá de medio de convocatoria a la acción transformadora de la realidad social.

La escritura de estas, tal como lo considera Gonzalo Portocarrero (2015) ocurrió "entre 1871 y 1879, cuando su autor residía en la hacienda familiar de Tútume en el valle de Mala" (2015: 145). Asimismo, Portocarrero, analizando este conjunto de poemas, postula que constituye un "intento de revaloración de la historia peruana" (2015: 145); y a la vez, encuentra que "el puntal de la poética de las Baladas es la toma de conciencia de la humanidad del indio" (2015: 146). En la poesía, González Prada no identifica modelos. La misma actitud tiene frente a la persona, pues no le satisface la narrativa romántica encabezada por Ricardo Palma.

La incorporación del indio como tema literario que caracteriza a las Baladas peruanas, fue un trabajo que recién se conoció en 1935, salvo algunas que se difundieron en 1873 en el Correo del Perú (1976: 77) o El mitayo, que pudieron ser leídas en las páginas de $E l$ Perú Ilustrado en su edición de 22 de marzo de 1890, según la apostilla incluida en la edición de la obra de González Prada por David Sobrevilla (2009: 582).

El año 1889 servirá para recibir la novela Aves sin nido de Clorinda Matto de Turner que en edición simultánea fue lanzada en Buenos Aires y Lima, según referencia de Alberto Tauro del Pino. (2001:1625, t.10).

Más allá de la poesía y la narrativa, el ambiente intelectual dota a la historia peruana del siglo XIX de la figura y la obra de Francisco de Paula González Vigil (1792-1875), quien tuvo una actuación política de civismo y moralidad ejemplares y posiciones ideológicas de cuestionamiento al poder eclesial y del gobierno del país, que también recalan en el artículo periodístico y en el libro. Cabe mencionar Defensa de la autoridad de los gobiernos contra las pretensiones de la curia romana, publicado en seis volúmenes entre 1848 y 1849 . Le sigue otra entrega en cuatro volúmenes en 1856, bajo el título de: Defensa de la autoridad de los obispos contra las pretensiones de la curia romana (Tauro, 2001:t.17). Es del caso agregar que estos escritos le ocasionaron dificultades con el Vaticano, a cuyas observaciones Vigil respondió con tres cartas dirigidas al propio Papa.
Sin pretender una mención de detalle, viene al caso indicar dos productos de la pluma de Vigil: Opúsculos sociales y políticos (1856) y Catecismo patriótico (1858). (Tauro, 2001:t.17)

Si bien las publicaciones mencionadas corresponden cronológicamente a la infancia de González Prada, la presencia vital de Vigil se prolonga hasta 1875, año en el que fallece en Lima, habiendo ejercido por años la dirección de la Biblioteca Nacional.

Resulta pertinente consignar la gran admiración que le profesó González Prada a Vigil, a quien le escribe un ensayo de reconocimiento y ponderación de su valentía, honestidad y transparencia en su vida y pensamiento. Tal es su entusiasmo y naturalidad en el elogio que en el último párrafo sintetiza su discurso diciendo: "En fin, por la fortaleza de carácter, por la sinceridad de convicciones, por lo inmaculado de la vida, Vigil redime las culpas de toda una jeneración. No tuvo rivales ni deja sucesores, i descuella en el Perú como solitaria columna de mármol a orillas de un río cenagoso" (Sobrevilla 2009:212).

Otro escritor más cercano en el tiempo, que expresa su pensamiento en el horizonte de la crítica social, política y religiosa, es Mariano Amézaga (1834-1894). Abogado de profesión y profesor universitario, también es ensalzado por González Prada. Su ensayo: Nuestros magistrados, se inicia con su nombre y sus cualidades singulares. Dice: "Mariano Amézaga fue no solo un escritor sincero y viril, sino un abogado de honradez proverbial, un verdadero tipo en la más noble acepción del vocablo. Si un mal litigante pretendía encomendarle la defensa de algún pleito inocuo, Amézaga le desahuciaba suavemente: "Amigo mío, como usted carece de justicia, yo no le defiendo" (Sobrevilla 2009:168). La continuación del texto marca el contraste en la conducta de Amézaga y la de los abogados y los jueces; y, a través de esta comparación subyacente, salta las virtudes de Amézaga. Él, contribuye a la captación de la realidad trágica de la educación en sucesivos artículos publicados en El Nacional a lo largo de un período comprendido entre 1867-1871. (Tauro, 2001, t.1 ${ }^{\circ}$ ).

Su mayor aporte en el plano ideológico se bifurca en lo religioso y en lo político. Se debe a dos libros sustantivos: Los dogmas fundamentales del catolicismo ante el tribunal de la razón (1873) que - como sostiene Tauro- provocó una secuela de censuras, protestas y reproches, así como los embates críticos de fray Pedro 
Gual, pues su actitud heterodoxa constituyó un reto a las creencias de la época" (2009: t.1). El segundo libro apunta a la realidad política y se titula: El proceso al civilismo (1882).

Con este panorama, sus lecturas de escritores franceses, ingleses y alemanes, indujeron a González Prada a labrarse su propio estilo, la elección de géneros y determinación de temas.

Los otros dos factores que moldearán su personalidad literaria serán la guerra contra los chilenos y la dantesca realidad desenterrada por la derrota con sus consecuentes invasión y mutilación del territorio. La posguerra oficia de palanca que lo impulsa de la poesía al ensayo y transforma al poeta lírico en el ensayista predicador reiterativo de la regeneración del país. También saltará de escritor enclaustrado y aislado al intelectual de actuación pública, pues no solamente publica, sino da conferencias en teatros e instituciones y participa activamente en la promoción intelectual a través del Círuclo literario, como vicepresidente, además de la conversión del escritor en político que le inspira la fundación del partido La Unión Nacional.

\section{El discurso en el Politeama}

\subsection{Noticias y precisiones}

Retiradas las tropas chilenas en 1883, González Prada inicia su nuevo rol de escritor con dos ensayos importantes: Grau y Vigil (1885) en los que anticipa, en fondo y forma, los lineamientos de su nueva literatura. Su primera conferencia la impartió en 1886 en el Ateneo. Si bien ya tiene rostro programático, atiende preferentemente el análisis literario peruano destacando sus debilidades como el de la imitación a imitadores mediocres al igual que su carácter de sometimiento y servilismo ante las dictaduras. "Semejante literatura no viene como lluvia de luciérnagas en noche tenebrosa, sino como danza de fuegos fatuos entre losas de cementerio", sentenciará en uno de sus párrafos. Esta mirada a la literatura peruana la desprende de la revisión de autores y obras europeos y españoles como metodología de estudio y explicación de la medianía de las artes literarias peruanas que se derivan de la baja calidad de los autores que adoptaron como modelos. Así como el Discurso tiene su antecedente inmediato, también tiene, manteniendo ambos su independencia textual, su continuador en la conferencia dictada en el teatro Olimpo.

El Discurso en el Politeama, leído en 1888, fue revisado por don Manuel para su inclusión en Pájinas Libres, habiendo sido objeto de "poquísimas correcciones", "simplificación ortográfica" y modificación de "unas pocas expresiones", tal como anota y ha estudiado Isabel Tauzin (2009).

Se ha escogido para este estudio el texto publicado en la edición del Congreso de la República bajo el cuidado de David Sobrevilla (2009), confrontándolo con el de Isabel Tauzin (2009).

\subsection{El texto}

Prada toma como motivo el acto público organizado por colegios de Lima con el fin de recaudar fondos encaminados al rescate de Tacna y Arica.

A partir de este hecho don Manuel da una mirada retrospectiva a la realidad social y política del país para vincularla con la causa de la derrota. El pasado es presentado por el autor como escenario de la ignominia en el que los gobernantes desfilan con su carga de ocultamiento de la verdad, con sus auténticos intereses, traiciones y carencia del sentido de patria, de justicia y libertad. Dirigieron el país consolidando una estructura social de exclusión del campesinado, que permanecía bajo la explotación y la servidumbre. Sin libertad no solo el indio sino los mestizos y los blancos, dentro de un ambiente de ignorancia generalizada, propiciaron una inclinación individual y social al servilismo, la adulación, la colusión, el acomodo y la convivencia con la arbitrariedad y el abuso de las dictaduras.

Ante este panorama expresa su condena a los viejos, actores del pasado y el fracaso y deposita su confianza en los niños y jóvenes, que bien educados en la ciencia, la verdad y la libertad, serán los redentores e impulsores del país hacia el progreso. De allí que, como arenga, moldee una frase que resuena como lema: " $i L o s$ viejos a la tumba, los jóvenes a la obra!", no solo en la literatura sino en la sociedad. ${ }^{1}$

1 Isabel Tauzin: “¡Los viejos, a la tumba, los nińos y los jóvenes, a la obra!” (2009:56). 


\subsection{El tema}

Está contenido en la presentación de la situación del país en la posguerra, que se palpa en la derrota, con nuestro territorio cercenado e invadido y todos los peruanos humillados por las tropas chilenas controlando las ciudades. Tal situación promovía el dolor y la tristeza, y conducía, a la vez, a pensar en el pasado para identificar a los culpables. Recordar esos personajes despertaba la indignación, la condena de sus generaciones y la confianza en las nuevas que, educadas en la ciencia y con libertad, corregirán los errores y conducirán al país a la recuperación de los territorios, a la integración nacional y al progreso.

\subsection{La estructura}

El Discurso en el Politeama descansa en una armazón dialogal implícita y responde a una concepción oral; es decir, para ser pronunciado con vehemencia, en voz alta, ante público, como arenga para convencer e inducir al cambio proponiéndose influir en la voluntad. Es una pieza de oratoria por el estilo, el tono, su lenguaje, su intención, así como por su sencillez y claridad de planteamiento. Su lectura en silencio y reflexiva viene a graficar una función complementaria porque todos sus componentes llevan a ser escuchados con un lenguaje impactante que sacude. Él, incluye en este mismo texto, las alusiones a su naturaleza oratoria. Dice: “... nosotros levantemos la voz para enderezar el esqueleto de estas muchedumbres encorvadas, hagamos por oxigenar esta atmósfera viciada con la respiración de tantos organismos infectos, i lancemos una chispa que inflame en el corazón del pueblo..." (Sobrevilla 2009: 241). Párrafos más abajo insistirá en el carácter oratorio de este ensayo: “¡Ojalá todas las frases repetidas en fiestas semejantes no sean melifluas alocuciones destinadas a morir entre las paredes de un teatro, sino rudos martillazos que retumben por todos los ámbitos del país!" (Sobrevilla 2009: 241). Aún podría decirse, que a continuación agrega otra precisión más: “¡Ojalá cada una de mis palabras se convierta en trueno que repercuta en el corazón de todos los peruanos y despierte los dos sentimientos capaces de regenerarnos y salvarnos: el amor a la patria i el odio a Chile!" (Sobrevilla 2009:241-242). Nótese las expresiones nada líricas ni de salón ni de solaz; son fuertes, duras, electrizantes: "levantemos la voz", "lancemos una chispa", "rudos martillazos", "mis palabras se conviertan en truenos". Además, en coherencia con la realidad social de ignorancia y analfabetismo, el Discurso, para que logre el efecto de crear conciencia para el cambio, tenía que sustentarse en su naturaleza oral, declamatoria.

La coloquialidad puede apreciarse cuando se dirige a los niños, conforme puede colegirse en el tercer, cuarto y quinto párrafo del apartado I. También hace lo propio con el público y así puede inferirse deteniéndonos en el tercer párrafo del apartado II; el segundo y tercero del III y en el séptimo del IV.

Otra pista de su línea dialogal se entresaca de la presencia de interrogaciones que de inmediato las contesta. Repárese en el apartado IV que comienza con una pregunta “¿Por qué desesperar?”. Luego, en el párrafo subsiguiente, retoma la interrogación al inicio para concatenarla con otras dos en su interior (Sobrevilla 2009:240).

El desarrollo de las ideas obedece a una exposición cíclica, ya que las toma en una parte y las retoma en otras, dentro de una tónica de repetición intencional y coherente con sus propósitos de sacudir para cambiar. Las ideas, entonces, no se desarrollan bajo un criterio de concentración lógica sino de exposición a saltos, imprimiéndole agilidad, martilleo y mantenimiento de la atención del oyente.

Formalmente, el autor ha dividido el texto en cuatro apartados, presididos por números romanos. En cuanto al fondo, es posible reconocer el exordio o introducción al tema que abarca el apartado I; la proposición, en la que vierte las ideas; la confirmación, que corre simultáneamente con la proposición; y, el epílogo, donde se sintetiza el argumento; materia del contenido del discurso oratorio, recogiendo las explicaciones de Emma González en su Diccionario de Terminología Literaria (2002: 118).

\subsection{El estilo}

El Discurso en el Politeama, no se presta a disimulos respecto a su filiación estética. Se inscribe dentro de la literatura política. Por las ideas se identifica su contenido político y por el lenguaje se reconoce su categoría literaria, perceptible en la elegancia de la expresión, el ritmo con compases de marcha y la musicalidad de imprecaciones, desafíos y combate.

La sintaxis es un flujo de oraciones compuestas de períodos largos, cargadas de adjetivaciones de colores contrastantes y temperatura muy alta. Yuxtapone una cláusula a otra, vinculadas con conjunciones que estiran las expresiones propias de un ánimo agitado y vehemente, con el tejido de coordinantes copulativos y 
disyuntivos que desembocan en un paisaje de redundancias, que le dan fuerza expresiva y belleza al discurso.

La percepción de la belleza descansa en la construcción predominante de la antítesis. El Discurso es una construcción de conceptos dicotómicos que señalan los extremos: niño-viejo; especialista-aficionado; orohierro; cielo-tierra; amor-odio; amigos-enemigos; etc. También el antagonismo se encuentra en los conceptos más allá de las palabras. El mensaje se ubica en el interior y se refuerza con los extremos. Corre por el cauce de la comparación sostenida en contrastes.

Su escritura y su prédica son de hipérbole y tremendismo; de convocatoria urgente y de tarea impostergable. Habla con indignación y esperanza. Condena el pasado y tiene fe en
El Discurso en el

Politeama, no se presta

a disimulos respecto a

su filiación estética. Se

inscribe dentro de la

literatura política. Por

las ideas se identifica su

contenido político y por

el lenguaje se reconoce

su categoría literaria,

perceptible en la elegancia

de la expresión, el ritmo

con compases de marcha

y la musicalidad de

imprecaciones, desafíos y

combate.
En este aspecto cabe precisar los dos planos del ensayo:

1. El de la realidad misma, de acuerdo a la cual la sociedad peruana excluía al indio como componente de la nación; y

2. El de la idea de González Prada que plantea la integración del Perú incorporando al indio.

Todo el tejido social está sumido en la ignorancia y el engaño; en la pasividad y la aceptación del abuso y la traición. Carece de libertades cívicas.

La anulación humana, social y cívica del indio tiene un operador oficial activo: “... la tiranía del juez de paz, del gobernador y del cura, esa trinidad embrutecedora del indio" (Sobrevilla 2009: 240).

El flagelo más grande que agravia al indio es la ignorancia y la servidumbre. Por eso, el futuro. Culpa a los viejos y alecciona a los niños. Deplora a los gobernantes y alerta a los gobernados y, por sobre su cólera, ama al Perú como su patria que merece la justicia y, a través de ella, la grandeza.

\section{El análisis}

\subsection{El enfoque}

González Prada examina y explica la realidad peruana, desde la perspectiva del gobernante-gobernado, configurando un retrato del país en su aspecto social y moral. El Discurso, es un espejo que muestra ante los ojos su rostro de atraso y tragedia. Puede esquematizarse en las siguientes ideas:

\section{a) Sobre la realidad social}

El Perú es un Estado integrado por indios y mestizos, no solo por criollos. Relacionando sociedad con geografía, a modo de síntesis, dice: "Indios de punas y serranías, mestizos de la costa, todos fuimos ignorantes y siervos; no vencimos ni podíamos vencer" (Sobrevilla: 2009: 239). clamando su redención asevera desafiante: "Trescientos años ha que el indio rastrea en las capas inferiores de la civilización, siendo un híbrido con los vicios del bárbaro y sin las virtudes del europeo: enseńadle siquiera a leer i escribir, i veréis si en un cuarto de siglo se levanta o no a la dignidad del hombre" (Sobrevilla 2009: 240).

La sociedad está dominada por la religión católica y el clero. Su influencia es amplia. No solo se queda en la educación en la edad escolar sino invade el hogar, envuelve al adulto y se infiltra en todas las manifestaciones de la vida social y política. González Prada contrapone a la religión la ciencia, porque esta impone una educación que entroniza "la libertad, esa madre engendradora de hombres fuertes". Además, para convencer alega los beneficios "de la ciencia positiva que en solo un siglo de aplicaciones industriales ha producido más bienes a la humanidad que milenios enteros de teolojía i metafísica" (Sobrevilla 2009: 239).

Reclama "la libertad para todos, i principalmente para los más desvalidos". A fin de que no quede como frase retórica, fundamenta su concepción integracionista e inclusiva, afirmando: "No forman el verdadero Perú 
las agrupaciones de criollos i extranjeros que habitan la faja de tierra situada entre el Pacífico y los Andes; la nación está formada por las muchedumbres de indios discriminadas en la banda oriental de la cordillera" (Sobrevilla 2009: 239-240).

b) Sobre el significado del tiempo y las generaciones

El pasado en cuanto escenario de los males, sirve de lección y de condena para que estos no se vuelvan a repetir. Por tal razón, hay que destruirlo combatiendo sin tregua hasta desaparecer toda huella que actúe como atavismo.

El presente es la época de transición. Corresponde alejarse de los vicios y sembrar las cualidades del progreso a través de la educación científica y laica. La verdad y la libertad deben desplazar a la conveniencia personal y el servilismo.

Es propio del futuro ser la estación de las realizaciones del hombre nuevo, educado en la ciencia y la libertad. En el futuro se alcanzarán los objetivos sembrados en el presente. Tiene como actores a los jóvenes y niños de hoy, que se han formado rompiendo con el pasado, sin los defectos de los viejos de entonces. Frente a esto, González Prada está convencido de que "En esta obra de reconstitución i venganza no contemos con los hombres del pasado: los troncos añosos i carcomidos produjeron ya sus flores de aroma deletéreo y sus frutas de sabor amargo. ¡Que vengan árboles nuevos a dar flores nuevas i frutas nuevas! ¡Los viejos a la tumba, los jóvenes a la obra!" (Sobrevilla 2009: 240).

González Prada recusa el pasado; valora el presente como el punto de partida del cambio y tiene fe en el futuro y en los jóvenes. Sosiega su ánimo, se serena y le da cabida a la espera. Esta recuperación de la tranquilidad lo motiva para iniciar el párrafo IV “¿Por qué desesperar? No hemos venido aquí para derramar lágrimas sobre las ruinas de una segunda Jerusalén, sino a fortalecernos con la esperanza. Dejemos a Boabdil llorar como mujer, nosotros esperemos como hombres." (Sobrevilla 2009: 240). Esta pausa al fragor en el ataque adquiere la imagen de reflexión en paz momentánea: "Nunca menos que ahora conviene el abatimiento del ánimo cobarde ni las quejas del pecho sin virilidad". Estas iluminaciones de la serenidad lo conducen a la referencia a la riqueza natural del país, pero la fuerza la pone en lo humano, por eso alude a la inteligencia de los peruanos que no tenemos "cerebros hotentotes" ni hemos sido hechos con "barro de Sodoma". Especialmente, la situación del indio es remediable a través de la educación. En consecuencia, se siente seguro cuando afirma: "Nuestros pueblos de la sierra son hombres amodorrados, no estatuas petrificadas." (Sobrevilla 2009:241).

González Prada en su Discurso ofrece su visión física del Perú aludiendo a la riqueza en sus recursos naturales. Su confianza y fe en los jóvenes y el futuro también se sustenta en la naturaleza. Primero se pregunta: "¿Por qué desalentarse? Nuestro clima i nuestro suelo ¿son acaso los últimos del Universo? En la tierra no hai oro para adquirir las riquezas que debe producir una sola Primavera del Perú" (Sobrevilla 2009: 240). Expresión elogiosa e hiperbólica que muestra su valoración de los recursos naturales y sus aspectos potenciales para ser aprovechados en el bienestar y progreso de los peruanos.

"El Perú fue cuerpo vivo, expuesto sobre el mármol de un anfiteatro, para sufrir las amputaciones de cirujanos que tenían ojos con cataratas seniles i manos con temblores de paralítico" (Sobrevilla 2009: 238), responde a la visión moral del Perú que expresa González Prada y que después persistirá en otros ensayos.

Significa la tragedia del país de ser conducido por gobernantes sin atributos morales y profesionales que con sus errores lo empujan al atraso. Se trata de políticos sin concepto ni amor a la patria, en quienes prevalecen sus intereses personales sobre los nacionales; que han gobernado sin integrar a la sociedad, sin educarla y envileciéndola con el engaño, el servilismo, sin libertad y sin derechos.

\section{c) La guerra como destape y detonante}

La guerra actuó como factor determinante para descubrir todas las lacras con las cuales convivía el pueblo peruano. Tenía millones de habitantes pero no ciudadanos; es decir, sin personas cívicamente activas con categoría de fuerza de control del poder y de participación pública en los asuntos del Estado. Esta ausencia de ciudadanía daba lugar a la disputa del gobierno, llevados por intereses personales 
y su envilecimiento en el cargo para gobernar con la intimidación y persecución propias de las dictaduras.

Todo esto permanecía sin ser notado en su real dimensión por la población hasta que se produjo la guerra, con su consecuente derrota y las secuelas de la invasión y mutilación de nuestro territorio. La guerra, entonces, permitió un darse cuenta del problema. Ante este hecho, correspondía la denuncia y el señalamiento de los culpables. Y ellos no podían ser otros que los gobernantes que fomentaron la ignorancia y el servilismo. De allí que él sentenciara: "La mano brutal de Chile despedazó nuestra carne i machacó nuestros huesos; pero los verdaderos vencedores, las armas del enemigo, fueron nuestra ignorancia i nuestro espíritu de servidumbre." (Sobrevilla 2009: 238).

\section{d) Emplazamiento al cambio}

El Discurso en el Politeama, materia de este estudio, está compuesto para dar directivas de acción. Los argumentos de Norberto Bobbio sobre las funciones del lenguaje en sus relaciones con el Derecho indica que tiene una función prescriptiva que se reconoce porque implica "dar órdenes, consejos, recomendaciones, advertencias, de suerte que influyan sobre el comportamiento de los demás y lo modifiquen y, en suma, para hacer lo que hay que hacer" (1998: 60).

Claro que este derrotero interpretativo se circunscribe al ámbito normativo, pero calza perfectamente en la oratoria del Discurso. Este, pues, está hecho para promover el cambio; es decir, la regeneración. Por eso, haciendo desfilar los males del pasado traza el camino para simultáneamente desprenderse de ellos y, a la vez, adquirir la nueva mentalidad, de la cual se obtendrá la nueva conducta cívica de los peruanos.

En este aspecto es reconocible el carácter prescriptivo del Discurso pues en él González Prada advierte, aconseja, recomienda, alerta, induciendo un camino único para superar la postración de la derrota: el cambio, apartándose de todas las malas prácticas causantes del desastre. Suena como órdenes morales que deben alcanzar la estructura de reglas cívicas de vida. Esta caracterización del Discurso explica un texto literario que incorpora la función prescriptiva del lenguaje, sin que su texto llegue a tener la configuración de una norma. Se trata de la función prescriptiva del lenguaje en la literatura, porque manteniendo su naturaleza estética persigue influir en el ánimo de los demás induciendo en una conducta y mentalidad de cambio. Toda la población peruana, conformada de hecho en tres sectores, indios, mestizos y criollos carecen de noción y amor a la patria y de la mentalidad y conducta de ciudadanía. Todos, por un factor u otro, asumen el pasivo de la derrota. De estos no se puede esperar ningún cambio. El único sector rescatable son los niños y los jóvenes, al que educándolos con la ciencia y libertad, son los depositarios de nuestra confianza en que alcanzarán el cambio.

El cambio está representado por la construcción de la ciudadanía, de la cual saldrán los verdaderos gobernantes; $y$, también, los gobernados conscientes de sus deberes y derechos que sabrán ejercer los mecanismos de control de poder con la opinión y la participación activa en los asuntos públicos del Estado.

Su exhortación y su tarea, serán incluidas en el tercer y cuarto párrafo del apartado I. Como para que tomen conciencia de su responsabilidad les sentencia: “... ninguna (generación) tuvo deberes más sagrados que cumplir, errores más graves que remediar ni venganzas más justas que satisfacer" (Sobrevilla 2009: 237). En contrapartida con los deberes que les señala resaltando la delicada misión que les cabe conseguir, los hará “... superiores a vuestros padres, tendréis derecho para escribir el bochornoso epitafio de una jeneración que se va, manchada con la guerra civil de medio siglo, con la quiebra fraudulenta i con la mutilación del territorio nacional." (Sobrevilla 2009: 237-38).

González Prada, incidiendo en la motivación del Discurso, caracteriza a la nueva generación precisándole que a ella le corresponde juzgar y castigar para corregir. Estas son sus palabras: "Los viejos deben temblar ante los niños, porque la jeneración que se levanta es siempre acusadora y juez de la jeneración que desciende" (Sobrevilla 2009: 237).

Es tarea de todos combatir la ignorancia y el servilismo con la acción de los niños y los jóvenes a la cabeza. El pueblo peruano tiene sus capacidades. González Prada está seguro que con buenos gobernantes y buenos ciudadanos la consumación de la trasformación será una realidad en el futuro. Con esa visión pregona: "Para ese gran día, que al fin llegará porque el porvenir nos debe una victoria, fiemos sólo en la luz de nuestro cerebro i en la fuerza de nuestros brazos." (Sobrevilla 2009: 240).

Los llamados al cambio pero por acción, no por omisión, indiferencia o conductas pasivas de dejar hacer y dejar pasar, se suceden en todo el Discurso. Está implícito en las comparaciones de contraste. 
Reiterativamente señala el cómo fue y el cómo debe ser, no como opción sino como conducta y participación activa y permanente. $Y$, no obstante que no es la frase de final del texto, su mensaje concluye en su arenga: “iLos viejos a la tumba, los jóvenes a la obra!”.

El emplazamiento, en consecuencia, es a los niños y a los jóvenes para que sean los actores del cambio, entendido como proceso que se logra en el tiempo. Para ello tienen que educarse en la ciencia y libertad. Les corresponde romper con la mentalidad del pasado y todas sus malas prácticas cívicas y morales. Ocurriendo así, nos llevarán al futuro de regeneración moral, cívica y política concebida como fórmula única para salvar al Perú.

\section{El comentario}

\subsection{El referente jurídico}

Gonzalez Prada compone el Discurso y lo da a conocer en 1888. Para esa fecha la Constitución Política de 1860 ponía el marco jurídico a la República, prescribiendo el concepto de Perú como Estado, nación y ciudadanía. Fue promulgada por Ramón Castilla como Presidente Constitucional del Perú el 13 de noviembre 1860. Proviene de la reforma de la Constitución de 1856 y a decir de Domingo García Belaunde "muy significativa por su contenido y larga duración, como en cierto sentido lo es la de 1933; ambas son las más importantes de los últimos cien años" (2006: 17, t.1). Rigió desde el mismo día de su promulgación "sin necesidad de juramento" (art. 138). Tendrá una interrupción de meses en 1867 por la promulgación de la Constitución de ese año, tal como sostiene Juan Vicente Ugarte del Pino (1978: 453).

Restablecida la vigencia de la Constitución de 1860, nuevamente enfrentará un paréntesis con la promulgación del Estatuto Provisionario de 1879 promovido por Nicolás de Piérola, autoproclamado Jefe Supremo de la República y que la coloca en un segundo plano. Firma esta disposición el 27 de diciembre de 1879, creando un Consejo de Estado y determinando su vigencia "mientras se den las instituciones definitivas a la República" (García Belaunde 2006: 67).

La inestabilidad jurídica no queda aquí. Miguel Iglesias, erigido Presidente Regenerador de la República, impone el Estatuto Provisionario de Cajamarca, promulgado el 9 de febrero de 1883, previa aprobación de la Soberana Asamblea del Norte del Perú reunida en Cajamarca. Fue su propósito contar con un marco legal para "Iniciar las negociaciones de paz exterior conforme a la ley de 29 de diciembre de 1882" (art. 23); "Nombrar Agentes Diplomáticos y Ministros Extraordinarios con plenos poderes para que negocien la paz con Chile, conforme a lo prescrito en la ley de 30 de diciembre de 1882" (art.24); y, "convocar a elecciones para el Congreso General Constituyente conforme a las leyes de 30 de diciembre último y 9 del presente" (art. 26). Cabe agregar que Miguel Iglesias fue Secretario de Estado en el Despacho de Guerra y que como tal firmó la promulgación del Estatuto Provisorio de 1879, expedido por Nicolás de Piérola al asumir la presidencia del Perú como Jefe Supremo de la República.

Volviendo a la Constitución de 1860 que sirve como norma jurídica de fondo de mayor jerarquía, cabe señalar que esta diseñaba un Estado confesional intolerante que protegía la religión católica, no permitiendo "el ejercicio público de otra alguna", cuyo compromiso de protección oficial perduró hasta 1915; año en el que se liberó el Estado, eliminando la persecución de cualesquier otro credo que no fuera el católico, mediante la ley no 2193 (García Belaunde 2006: 10 t.2).

El texto constitucional de 1860 consideraba la nación peruana como "la asociación política de todos los peruanos" (art. 1) no obstante que en la realidad estaba excluida la masa campesina de la composición social y política del país ya que sus miembros no elegían ni podían ser elegidos para cargos del gobierno.

Según el artículo 34, son peruanos "los que nacen en el territorio de la República” (inciso 1\%); y, en cuanto tal, todo peruano estaba "obligado a servir a la República con su persona y sus bienes...” (art. 36).

Aunque todos los nacidos en el territorio son peruanos, para ser ciudadano se requería haber cumplido los veintiún años de edad. Pero, para ejercer el sufragio la norma constitucional en el artículo 38 exigía que los ciudadanos debían saber leer, escribir o ser "jefes de taller", o tener "alguna propiedad raíz", o pagar "al tesoro público alguna contribución"; requisitos que no poseían los campesinos, sumidos en la dependencia social y económica por la explotación y la servidumbre. En 1895 mediante ley de 12 de noviembre se modificó este artículo, restringiendo el derecho de sufragio a la condición de alfabeto; es decir, que supiera leer y escribir, eliminando los otros condicionantes socioeconómicos, patrimoniales y tributarios. 
El gobierno se define como "republicano, democrático, representativo, fundado en la unidad" (artículo 42) y para ser presidente, ministro; diputado o senador tenía como condición previa insalvable el ser ciudadano activo; es decir con derecho de sufragio, lo que implicaba saber leer y escribir. Consecuentemente, los campesinos que conformaban las mayorías nacionales estaban excluidos de la función pública como gobernantes y tampoco podían elegir, por ser analfabetos.

\subsection{Por la conciencia jurídica}

Del texto del Discurso queda en evidencia que el Perú tiene una población con mayores de edad, pero sin ciudadanía debido al generalizado analfabetismo, explicado a través del concepto de ignorancia, que los excluía de su ejercicio pasivo como electores y su ejercicio activo como gobernantes. Esta situación social es el resultado de los malos gobernantes que no impulsaron programas de educación pública masiva; y, específicamente, de la educación científica que sí viene a ser soporte de la inclusión y la democracia.

Antes de la guerra con Chile y de manera especial no había sido percibida en su dramatismo e importancia. Por eso, en pos de una reconstrucción nacional era la causa prioritaria a atender y resolver. Preferentemente había que educar en ciencia y libertad a los niños y los jóvenes en tanto generación del reemplazo en la dirección del país. Entonces, había la necesidad inmediata de, a través de la educación, construir ciudadanía con sus deberes y derechos prefijados y calificados como sagrados.

Para levantar el ánimo de una sociedad sumida en la derrota con la humillación de la presencia enemiga en todo el territorio, González Prada sentía la necesidad de predicar el patriotismo y la democracia. Tenía que localizar su pensamiento y su palabra en el Derecho como medio seguro de conquistar la igualdad ante la ley y el ejercicio activo de la ciudadanía, enmarcada con un sólido concepto de patria y de ferviente amor a ella.
Cuando trae a colación los males del pasado satisface la necesidad intelectual de señalar las causas y a la vez el punto de partida del cambio insoslayable, de vida o muerte, para la subsistencia del Perú como nación. González Prada reconoce la inexistencia de la formación política dentro del concepto de ciudadanía, no solo por falta de educación científica sino por la carencia de partidos que dinamicen la actividad social y cívica. Con toda claridad constata y denuncia que "nunca hubo un verdadero partido liberal ni un verdadero partido conservador, sino tres grandes divisiones: los gobiernistas, los conspiradores i los indiferentes por egoísmo, imbecilidad o desengańo" (Sobrevilla 2009: 239).

En el afán de retratar la situación lamentable de la sociedad peruana hasta antes de la guerra, abordando sus dos campos: el de los gobernantes y el de los gobernados, González Prada asevera: "La historia de muchos gobiernos del Perú cabe en tres palabras: imbecilidad en acción; pero la vida toda del pueblo se resume en otras tres: versatilidad en movimiento" (Sobrevilla 2009: 241).

Si la conciencia se define como la capacidad del autoconocimiento y del conocimiento de los otros, en las postulaciones oratorias del Discurso, González Prada, al percatarse de la derrota en la guerra de 1879 y de sus causas, elabora su propia conciencia de la situación que enfrenta la población del Perú y se forja su propio rol de ciudadano y de intelectual de abandonar su pasividad, su autoexclusión del ejercicio ciudadano y decide pasar él mismo a la acción política que comienza por denunciar los males y proponer las soluciones. Este primer momento de la misión social que se autoimpone viene a constituir la formación de la conciencia moral en él mismo y desde él mismo, considerando como deber personal ineludible para alcanzar el bien común y el sentimiento de ser y de pertenencia a una nación llamada a vivir en alto nivel y de mejor forma.

Esta conciencia moral de su misión lo palanquea hacia la transformación en un trabajo permanente de insistencia 
para colocar en la conciencia de los demás ese sentido de la misión ciudadana fomentando el cambio en la mentalidad y en la conducta. El argumento que los convencerá pasa a sustentarse en que el ser ciudadano implica deberes y derechos; es decir, obligaciones de cada uno para con el conjunto. La concepción jurídica de la ciudadanía le otorga títulos a la persona, le pone la base de su actuación ciudadana que le depara conductas en el plano del gobernante y del gobernado.

Como gobernado le corresponde ejercer el control con su participación en los asuntos públicos; con el ejercicio de sus derechos de opinión, de petición pública, de asociación, de libertad religiosa, de educación; de igualdad de las personas. Como gobernante, en su compromiso de amar a su patria, la responsabilidad política, la honestidad pública en el manejo de los bienes, la hacienda pública; el reconocimiento y respeto a la libertad; y garantizar la recta administración de justicia; crear las condiciones de bien común y de verdadera soberanía; en buena cuenta, entrar a la función pública para servir al país no para servirse de él en beneficio propio. Auténticamente tiene que ser un gobernante de corte republicano, representativo y democrático y, para la coyuntura histórica de la derrota, debe de incorporar a la sociedad y la ciudadanía al "indio" educándolo y dándole libertad al igual que a los "mestizos", los "criollos" y a todos, "principalmente" para los más desvalidos"

La causa que se autoimpuso de predicar el cambio solo podía tener resultados efectivos y eficaces, predicándolo con una literatura política de acción, como construcción de ciudadanía en cuyo interior se tejería la trama de los deberes y derechos de cada cual.

Si como moldea la teoría "Cualquier ser humano, sin necesidad de formación jurídica alguna, sabe lo que es su derecho y cuando se le infiere un daño injusto, así como cuál es el derecho ajeno y siente la necesidad de respetarlo" (Faunoux, María g., 2001:47), con mayor razón Manuel González Prada que con su inteligencia, su educación, personalidad, conducta moral y ejercicio de los valores cívicos y políticos, podía asumir por sí mismo el rol de liderar el resurgimiento del Perú, superando la derrota sobre la base de inculcar la transformación de una población en ciudadanía, basada en la conciencia del ejercicio simultáneo de la acción hacia el cambio como deber y como derecho.

Emilio Barrantes, el pedagogo insigne, desde la óptica pedagógica advierte que "González Prada fue emergiendo como la conciencia de un pueblo
Del texto del Discurso queda en evidencia que el Perú tiene una población con mayores de edad, pero sin ciudadanía, debido al generalizado analfabetismo explicado a través del concepto de ignorancia, que los excluía de su ejercicio pasivo como electores y su ejercicio activo como gobernantes. Esta situación social es el resultado de los malos gobernantes que no impulsaron programas de educación pública masiva $y$, específicamente, de la educación científica que sí viene a ser soporte de la inclusión y la democracia.

inexistente aún pero previsible. $\mathrm{Ni}$ un pueblo ni un individuo existen realmente si no tienen conciencia de sí mismos y de la realidad a la cual pertenecen. Sin embargo, el hecho de tener conciencia en medio de una multitud que no la tiene, condena a su poseedor a una suerte de ostracismo en su propia tierra, a la soledad y la malquerencia de quienes se sienten heridos en su apetitos y en sus intereses".

"González Prada termina por ser uno contra todos; por ser el dedo acusador y la voz independiente y veraz en un medio hecho al halago, la buena vida, las apariencias y el engaño" (1999: 240).

En suma:

El Discurso en el Politeama es un texto de literatura política, tipificado como una arenga en tanto "Discurso pronunciado para enardecer los ánimos de los oyentes" (Diccionario de la lengua espańola, 2014); y, a la vez, proclama, a partir de su naturaleza de "Alocución política o militar de viva voz o por escrito", que así define la Real Academia Española en su Diccionario 2014.

El Discurso es el medio literario por el cual González Prada inicia una campaña intelectual y cívica de 
liderar el cambio, la regeneración del pueblo peruano, buscando crear una conciencia colectiva de ciudadanía y una conciencia individual en cada ciudadano basada en el ejercicio de los deberes y derechos en tanto servicio y rol social por el bien común y el desarrollo del Perú en libertad, integración, igualdad y justicia.

Manuel González Prada es el ejemplo del intelectual que responde a la realidad social de la coyuntura histórica y asume su rol político como escritor en una sociedad signada por la exclusión, la desigualdad, la ignorancia y la ausencia de ciudadanía. Es su función denunciar, explicar y orientar hacia el futuro. Señalar los defectos es el puente para llevar a la convicción del cambio.

Sobre González Prada cabe decir parafraseando su homenaje a Vigil: No tuvo iguales ni en su tiempo ni después y en la historia de la literatura peruana y de las ideas brilla con los fulgores del astro que iluminó el camino para superar el presente de atraso hacia el futuro de realización de los ideales de patria, justica y honestidad pública.

\section{Bibliografía}

1999, BARRANTES, Emilio. El Perú vivo, Universidad Nacional Federico Villarreal, Lima.

1998, BOBBIO, Norberto. Teoría General del Derecho, Traducción Eduardo Rozo, Editorial Debate, 5a reimpresión, Madrid.
2001, FAUROUX, María g., Ideas para introducción al Derecho, Abeledo - Perrot, Buenos Aires.

2006, GARCÍA BELAUNDE, Domingo, Las Constituciones del Perú, Universidad San Martín de Porres, Lima 2 t.

2002, GONZÁLEZ DE GAMBIER, Emma Diccionario de terminología literaria, Editorial Síntesis, Madrid.

2015, PORTOCARRERO, Gonzalo, La urgencia por decir "nosotros” Pontifica Universidad Católica del Perú, Lima.

2014, REAL ACADEMIA ESPAÑOLA Diccionario de la lengua española, Colombia, 2 ta.

1976, SÁNCHEZ, Luis Alberto, Mito y realidad de González Prada, P.L. Villanueva Editor, Lima

2009 SOBREVILLA, David, Manuel González Prada, Los jóvenes a la obra, Estudio preliminar, selección y notas, congreso del Perú, Lima

2001 TAURO DEL PINO, Alberto, Enciclopedia ilustrada del Perú, PEISA, Lima, 17t.

2009 TAUZIN - CASTELLANOS, Isabelle, Manuel González Prada, Ensayos 1885 -1916, Edición Introducción y notas - Universidad Ricardo Palma, Lima.

1978 UGARTE DEL PINO, Juan Vicente, Historia de las Constituciones del Perú, Editorial Andina, Lima

2003 ZANUTELLI, Rosas, Manuel, La saga de los González Prada, Universidad Ricardo Palma, Lima

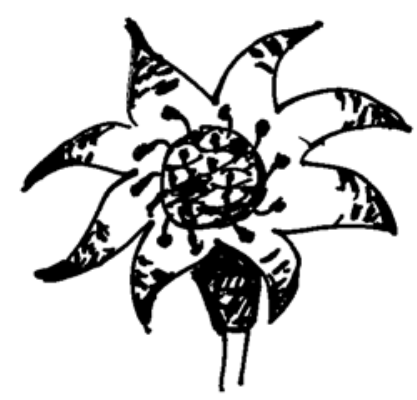

